\title{
Перестраиваемый вращением монолитный двухлучевой интерферометр с неподвижным фотоприемником
}

\author{
В.Д. Угожаев \\ Институт автоматики и электрометрии СО РАН \\ *E-mail: vdu@iae.nsk.su
}

DOI:10.31868/RFL2018.128-129

Двухлучевые интерферометры со сходящимися пучками находят широкое применение в оптике и фотонике, например, в интерференционной фотолитографии для создания периодических структур с масштабом вплоть до 10 нм [1] и для исследования голографических материалов. Традиционная конфигурация [2], включающая светоделитель и два юстируемых зеркала, сложна в эксплуатации и позволяет только дискретно изменять период интерференционной картины (ИК). Концепция вращательной перестройки периода, предложенная в [3-5] и дополненная идеей стабилизации положения ИК относительно светоделителя [6,7], полностью снимает указанные недостатки. В [3] рассмотрен монолитный двухлучевой интерферометр (МДИ) с вращательной перестройкой, который включает в себя только светоделительный кубик (СДК); он очень удобен в работе с углами схождения до $60^{\circ}$ благодаря своей компактности. Однако описанная в [3] конфигурация предусматривает согласованное с вращательной перестройкой линейное перемещение фотоприемника. Настоящий доклад посвящен анализу МДИ с неподвижным относительно СДК фотоприемником (НФП).

На рис. 1 представлена оптическая схема записи голографической решетки с МДИ. На ней отображены источник излучения 1, СДК 2 с делительным зеркалом 3 и НФП 4. Коллимированный световой пучок (КСП) 5 диаметром $D$ от источника 1 падает на грань $\mathrm{C}_{1} \mathrm{C}_{2}$ под углом $\theta$, входит в СДК под углом преломления $\psi$ и расщепляется делительным зеркалом на два парциальных пучка 6 и 7, выходя-

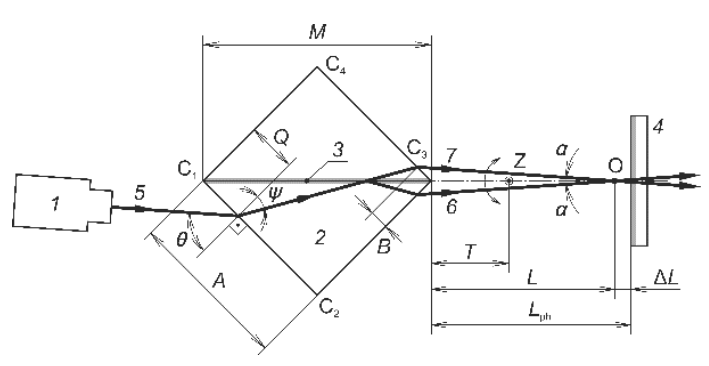

Рис. 1. Оптическая схема МДИ щие из СДК под углом схождения $2 \alpha$ друг к другу, формируя ИК в области их перекрытия. Из рис. 1 ясно, что $\alpha=\theta-45^{\circ}$, откуда следует условие схождения $\theta>45^{\circ}$. Оси парциальных пучков пересекаются в точке $O$ на расстоянии $L$ от ребра $\mathrm{C}_{3}$, смещенной от НФП на малое расстояние $\delta L=L-L_{\mathrm{ph}}$ (далее длина схождения). Если МДИ вращается вокруг оси $\mathrm{Z}$, удаленной от ребра $\mathrm{C}_{3}$ на расстояние $T$, относительно своего базового положения, характеризующегося входными параметрами КСП $\theta=\theta_{0}$ и $Q=Q_{0}$, то длина схождения будет изменяться согласно следующей формуле:

$$
L=\frac{(T+M)\left(\sin \theta-\cos \theta-\sin \theta_{0}+\cos \theta_{0}\right)+M(1-\operatorname{tg} \psi) \cos \theta-\sqrt{2} Q_{0} \cos \theta_{0}}{\sin \theta-\cos \theta}
$$

Задача состоит в том, чтобы для заданного $\theta_{0}$ найти такие значения расстояний $Q_{0}$ и $T$, которые дали бы минимальные вариации длины схождения при движении КСП по входной грани СДК от нижнего $\theta_{1}$ до верхнего $\theta_{2}$ граничных значений угла падения. Нижняя граница обусловлена касанием КСП, вошедшего в 
СДК, края $\mathrm{C}_{3}$ делительного зеркала 3 , а верхняя - касанием края $\mathrm{C}_{1}$. При наличии трех неизвестных: $Q_{0}, \theta_{1}$ и $\theta_{2}$ - составляются три уравнения. Одно из них основывается на условии касания КСП диаметром $D_{0}$ краев делительного зеркала. Два других строятся по условию малости смещения $\delta L$ на границах и в точке экстремума зависимости $L(\theta)$, которая совмещается с базовым положением. Соответствующие длины схождения $L_{i}$ вычисляются по формуле (1) с подстановкой $\theta=\theta_{i}$, где $i=0,1$ и 2 . Критерием малости является ограничение допуском $\eta \ll<1$ наибольших по модулю значений относительного смещения, присущих указанным положениям:

$$
2\left|\delta L_{i}\right| / S_{i}=\eta
$$

где $S_{i}=D_{0} / \sin \alpha_{i}$ —продольная по ходу парциальных пучков длина ИК.

Решение данной системы уравнений для четырех значений диаметра КСП при показателе преломления $n=1,5183$ (стекло К $8, \lambda=546,07$ нм) материала СДК и $\eta=0,1$ отображено на рис. 2 : показаны зависимости $\alpha_{1}\left(\theta_{0}\right)$ (кривые $1,4,7$ и 10), $\alpha_{2}\left(\theta_{0}\right)$ (кривые $2,5,8$ и 11) и ширины диапазона $\Delta \alpha\left(\theta_{0}\right)=\alpha_{2}-\alpha_{1}$ (кривые $3,6,9$ и 12) при $D_{0} / A=0,065 ; 0,1 ; 0,15$ и 0,2 соответственно. Например, для $D_{0} / A=0,065$ (при $A=20 \mathrm{мм}$ диаметр $D_{0}=1,3$ мм) и базового угла падения $\theta_{0}=56^{\circ}$ ширина диапазона $\Delta \alpha=11,9^{\circ}$; угол $\alpha$ изменяется в интервале $6,24^{\circ}-18,12^{\circ}$, что означает отношение периодов ИК $\Lambda_{1} / \Lambda_{2}=2,86-$ полторы октавы. Даже для КСП большого диаметра - $D_{0} / A=0,2\left(D_{0}=4\right.$ мм $)$ интервал перестройки угла $\alpha=3,54^{\circ}-5,61^{\circ}, \Delta \alpha=2,08^{\circ}$ и $\Lambda_{1} / \Lambda_{2}=1,56$. На рис. 2 показана также зависимость $\alpha_{\mathrm{m}}\left(\theta_{0}\right)$ (кривая 13) для пучка диаметром $D_{0}=D_{\mathrm{m}}$, заполняющим всю длину $M$ дели-

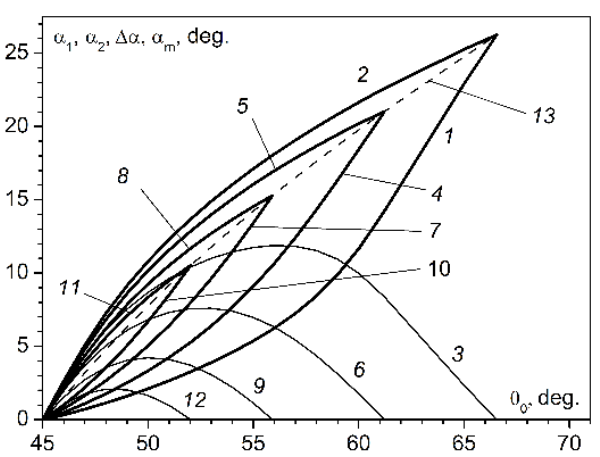

Рис. 2. Граничные значения угла $\alpha$ и ширина диапазона $\Delta \alpha$ его перестройки в зависимости от базового угла падения $\theta_{0}$. тельного зеркала, в этом случае $\alpha_{1}=\alpha_{2}$. Эти перестроечные характеристики сильно зависят от показателя преломления. Так, если $n=2,2$, то для КСП диаметром $D_{0}=1$ мм с $\theta_{0}=60^{\circ}$ ширина диапазона $\Delta \alpha=23,75^{\circ}$, граничные значения $\alpha_{1}=6,63^{\circ}$ и $\alpha_{2}={ }^{\circ} 30,38^{\circ}$, соответствующее отношение периодов ИК 4,38 - более двух октав; в итоге имеет место двукратное превышение предыдущего примера по $\Delta \alpha$.

Приведенные расчетные данные указывают на весьма малую кривизну зависимости $L(\theta)$ и соответственно на высокую эффективность концепции вращательной перестройки в МДИ с НФП. Такой интерферометр очень компактен: его габариты ограничиваются размерами СДК совместно с фотоприемником, кроме того, он практически не подвержен вибрациям.

\section{Литература}

[1] C. Lu, R.H Lipson, Laser Photonics Rev. 4, 568-580 (2010)

[2] В.В. Шелковников, Е.В. Васильев и др., Оптика и спектроскопия 99, 806-815 (2005)

[3] С.Л. Микерин, В.Д. Угожаев, Оптика и спектроскопия 111, 1019-1025 (2011)

[4] С.Л. Микерин, В.Д. Угожаев, Автометрия 48, № 4, 20-32 (2012)

[5] S.L. Mikerin, V.D Ugozhaev. In: Interferometers: Fundamentals, Methods and Applications, Nova Science Publishers, 2015, 277 p. Ch. 7-9. P. 173-210.

[6] В.Д. Угожаев, Автометрия 52, № 2, 57-65 (2012)

[7] В.Д. Угожаев. Двухлучевой интерферометр. Патент РФ на изобретение № 2626062, Изобретения. Полезные модели № 21 (2017) 